\title{
Pola Distribusi Kekeringan Menggunakan Metode Standardized Precipitation Index (SPI) di Kalimantan Barat
}

Ismi Rizqi Qonita ${ }^{a^{*}}$, Yoga Satria Putra ${ }^{a}$ Arie Antasari Kushadiwijayanto ${ }^{b}$

aProdi Geofisika, FMIPA Universitas Tanjungpura, Pontianak

bProdi Ilmu Kelautan, FMIPA Universitas Tanjungpura, Pontianak

*Email : ismirizqi5@gmail.com

\begin{abstract}
Abstrak
Penelitian tentang analisis tingkat kekeringan di Provinsi Kalimantan Barat telah dilakukan menggunakan metode Standardized Precipitation Index (SPI). Penelitian ini menggunakan data curah hujan selama 32 tahun (1985-2016) dari European Centre for Medium-range Weather Forecast (ECMWF). Curah hujan menjadi satu-satunya parameter masukan dalam metode Standardized Precipitation Index (SPI), sehingga tingkat kekeringan yang dikaji hanya dipengaruhi oleh peningkatan dan penurunan jumlah curah hujan. Dari analisa yang dilakukan selama periode 32 tahun, kekeringan terparah terjadi pada tahun 2014 di daerah Kabupaten Ketapang, 2015 di daerah Kabupaten Ketapang dan 2016 di daerah Kabupaten Sambas.
\end{abstract}

Kata Kunci : Curah Hujan, Kekeringan, SPI

\section{Latar Belakang}

Kalimantan Barat merupakan salah satu wilayah yang sering mengalami kekeringan. Kekeringan terjadi karena penurunan jumlah curah hujan akibat adanya perubahan iklim dan cuaca, seperti fenomena El-Nino dan La-Nina [1]. Suatu wilayah beriklim tropis ditandai dengan panas dan bercurah hujan tinggi sepanjang tahun dan cenderung memiliki dua musim yaitu musim hujan dan musim kemarau, musim hujan terjadi sekitar bulan Oktober hingga April, sedangkan musim kemarau terjadi sekitar bulan April hingga Oktober [2]. Peningkatan suhu udara dan penurunan curah hujan di Kalimantan Barat dalam kurun waktu yang cukup lama akan mengakibatkan kekeringan.

Penelitian-penelitian menggunakan metode Standardized Precipitation Index (SPI) telah banyak dilakukan. Diantaranya adalah penelitian tentang tingkat kekeringan lahan gambut di Pulau Tebing Tinggi, Provinsi Riau. Penelitian ini menyimpulkan bahwa semakin kecil nilai curah hujan maka nilai SPI juga akan semakin kecil [3]. Selanjutnya penelitian tentang tingkat kekeringan meteorologi di Pulau Bengkalis menggunakan metode SPI, telah menyimpulkan bahwa kekeringan yang terjadi pada tahun 2014-2016 [4]. Penelitian-penelitian yang telah dilakukan tersebut selanjutnya menjadi dasar untuk melihat kekeringan di wilayah Kalimantan Barat menggunakan metode SPI.

Pada penelitian kali ini telah dilakukan analisa tentang tingkat kekeringan di wilayah Kalimantan Barat dengan menggunakan metode SPI. Studi ini bertujuan untuk melihat sebaran tingkat kekeringan yang terjadi di Kalimantan Barat berdasarkan nilai indeks SPI dengan data curah hujan selama periode 32 tahun (19852016). Manfaat dari penelitian yang dilakukan adalah sebagai informasi tentang pola distribusi kekeringan di wilayah Kalimantan Barat

\section{Metodologi}

\subsection{Daerah Kajian}

Daerah kajian dalam penelitian ini adalah Provinsi Kalimantan Barat pada koordinat $2^{\circ} 08$ LU sampai $3^{\circ} 05$ LS dan $108^{\circ} 0$ BT sampai $114^{\circ} 10$ BT. Kalimantan Barat dipilih menjadi wilayah penelitian karena mengacu pada data kebakaran hutan yang terjadi pada tahun 2013-2018 di daerah tersebut seperti yang ditunjukkan pada Gambar 1.

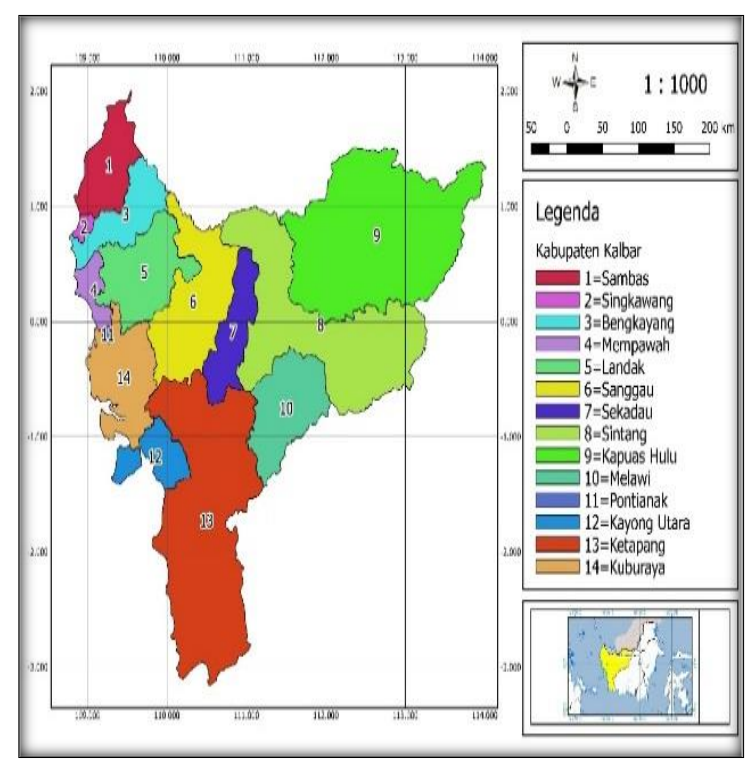

Gambar 1. Daerah Kajian Penelitian Kekeringan 


\subsection{Data Penelitian}

Data yang digunakan pada penelitian ini adalah data sekunder berupa data curah hujan harian periode tahun 1985-2016. Data curah hujan diperoleh dari data European Centre for Medium-range Weather Forecast (ECMWF) yang dapat diunduh pada laman resmi ECMWF Data curah hujan ECMWF yang terunduh berformat netCDF, yang harus diubah terlebih dahulu ke format CSV agar dapat digunakan dalam perhitungan. Berikut ini laman dari ECMWF http://apps.ecmwf.int/dataset/data/interim-fulldaily/.

\subsection{Metode Standardized Precipitation Index (SPI)}

Nilai indeks SPI yang dihasilkan dari perhitungan selanjutnya akan diklasifikasikan dalam beberapa kategori, berdasarkan pada Tabel 1 [5] :

Tabel 1. Klasifikasi Nilai Index SPI

\begin{tabular}{cc}
\hline Nilai SPI & Kategori \\
\hline$\geq 2$ & Sangat basah \\
$1.50 \mathrm{~s} / \mathrm{d} 1.99$ & Basah \\
$1 \mathrm{~s} / \mathrm{d} 1.49$ & Agak basah \\
$-0.99 \mathrm{~s} / \mathrm{d} 0.99$ & Normal \\
$-1 \mathrm{~s} / \mathrm{d}-1.49$ & Agak kering \\
$-1.49 \mathrm{~s} / \mathrm{d}-1.99$ & Kering \\
$\leq-2$ & Sangat kering \\
\hline
\end{tabular}

Tingkat kekeringan suatu wilayah ditentukan menggunakan formulasi perhitungan indeks SPI. Indeks SPI didefinisikan sebagai fungsi frekuensi atau peluang kejadian yang dinyatakan dalam persamaan berikut :

$$
g(x)=\frac{1}{\beta^{\alpha} \Gamma(\alpha)} x^{\alpha-1} e^{-x / \beta}
$$

dengan, $\mathrm{g}(\mathrm{x})$ adalah distribusi gamma yang banyak digunakan dalam percobaan probabilitas dimana hasilnya berupa suatu distribusi, $\Gamma(\alpha)$ adalah fungsi gamma, $\alpha>0$ adalah parameter skala, $\beta>0$ adalah parameter bentuk, dan $\mathrm{X}>0$ adalah jumlah curah hujan. Nilai $\alpha$ dan $\beta$ ditentukan untuk dengan menggunakan persamaan sebagai berikut [5] :

$$
\begin{aligned}
& \alpha=\frac{1}{4 \mathrm{U}}\left(1+\sqrt{1+\frac{4 \mathrm{U}}{3}}\right) \\
& \mathrm{U}=\operatorname{Ln}(\overline{\mathrm{x}})-\frac{\sum \operatorname{Ln}(\mathrm{x})}{\mathrm{N}} \\
& \beta=\frac{\overline{\mathrm{x}}}{\alpha}
\end{aligned}
$$

dengan $\mathrm{N}$ adalah jumlah data pengamatan curah hujan.
Parameter yang dipergunakan untuk menentukan probabilitas komulatif dari kejadian curah hujan yang diamati untuk setiap bulan dan skala waktu dari tiap stasiun dihitung dengan persamaan berikut [5]:

$$
G(x)=\int_{0}^{x} g(x) d x=\frac{1}{\beta^{\alpha} T(\alpha)} \int_{0}^{x} t^{\alpha-1} e^{-x / \beta} d x
$$

dengan $\mathrm{G}(\mathrm{x})$ adalah jumlah distribusi yang di akumulasi. karena fungsi gamma tidak terdefinisi untuk $\mathrm{x}=0$, maka nilai $\mathrm{G}(\mathrm{x})$ menjadi:

$$
H(x)=q+(1-q) \times G(x)
$$

dengan q adalah jumlah kejadian hujan.

Perhitungan $\mathrm{Z}$ atau SPI untuk $0<\mathrm{H}(\mathrm{x}) \leq 0,5$ dilakukan dengan persamaan sebagai berikut:

$$
\mathrm{Z}=\mathrm{SPI}=-\left(\mathrm{t}-\frac{\mathrm{c}_{0}+\mathrm{c}_{1} \mathrm{t}+\mathrm{c}_{2} t^{2}}{1+\mathrm{d}_{1} \mathrm{t}+\mathrm{d}_{2} t^{2}+\mathrm{d}_{3} t^{3}}\right)
$$

dengan:

$$
\mathrm{t}=\sqrt{\operatorname{Ln}\left(\frac{1}{(\mathrm{H}(\mathrm{x}))^{2}}\right)}
$$

sedangkan perhitungan $\mathrm{Z}$ atau SPI untuk $0,5<$ $\mathrm{H}(\mathrm{x}) \leq 1,0$, dilakukan dengan persamaan sebagai berikut:

$$
\mathrm{Z}=\mathrm{SPI}=-\left(\mathrm{t}-\frac{\mathrm{c}_{0}+\mathrm{c}_{1} \mathrm{t}+\mathrm{c}_{2} t^{2}}{1+\mathrm{d}_{1} \mathrm{t}+\mathrm{d}_{2} t^{2}+\mathrm{d}_{3} t^{3}}\right)
$$

dengan:

$$
\mathrm{t}=\sqrt{\operatorname{Ln}\left(\frac{1}{(1-\mathrm{H}(\mathrm{x}))^{2}}\right)}
$$

dimana $c_{0}=2,515517, c_{1}=0,802853, c_{2}=$ $0,010328, \mathrm{~d}_{1}=1,432788, \mathrm{~d}_{2}=0,189269$ dan $\mathrm{d}_{3}=$ 0,001308

\section{Hasil dan Pembahasan}

\subsection{Pola Distribusi Kekeringan Tahun 2014}

Pada Gambar 2 untuk tahun 2014 nilai SPI terkecil bernilai -1.49 dikategorikan agak kering dengan curah hujan sebesar $3552 \mathrm{~mm}$, terjadi di Kabupaten Ketapang. Adanya fenomena monsoon Australia yang terjadi di Kalimantan Barat mengakibatkan curah hujan menurun khususnya di Kabupaten Ketapang. Selain monsoon Kabupaten Ketapang mengalami penurunan intensitas curah hujan dikarenakan oleh fenomena El-Nino lemah, pada fase El-Nino curah hujan di Kabupaten Ketapang cenderung rendah, hal inilah yang menyebabkan Kabupaten Ketapang pada tahun 2014 mengalami kekeringan [6]. 


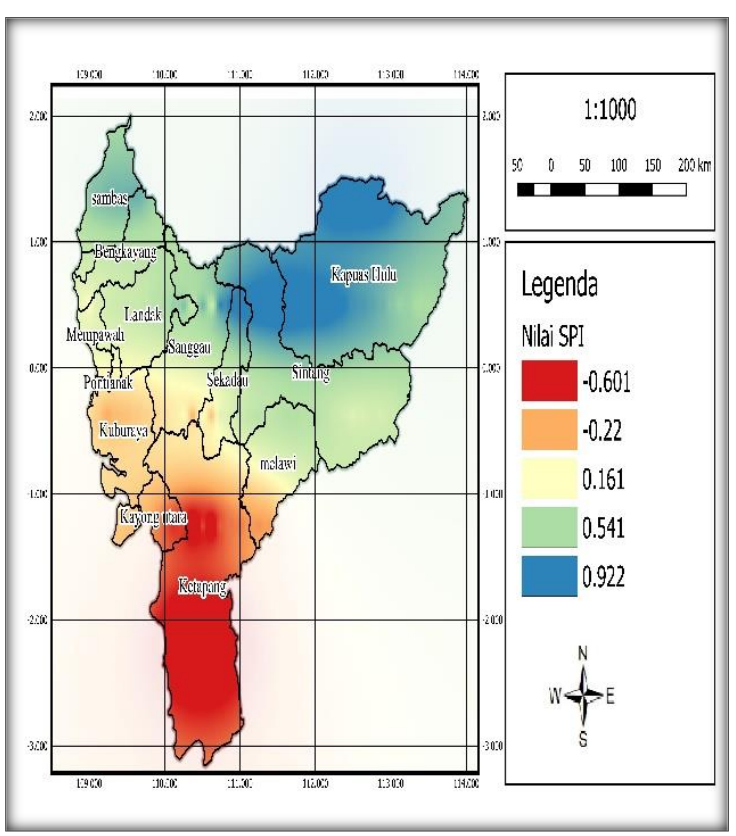

Gambar 2. Sebaran Kekeringan Tahun 2014

\subsection{Pola Distribusi Kekeringan Tahun 2015}

Pada Gambar 3 untuk tahun 2015 nilai SPI terkecil bernilai-1.306 dikategorikan agak kering dengan curah hujan $3862 \mathrm{~mm}$, yang terjadi di Kabupaten Ketapang. Terjadinya fenomena monsoon Australia yang mengakibatkan curah hujan menurun di Kalimantan Barat khususnya Ketapang [7]. Fenomena lain seperti juga terjadi ditahun 2015, pada fase El-Nino tersebut angin meridional yang berhembus dari timur-barat membawa sedikit uap air, hal inilah yang menjadi penyebab kekeringan di Kabupaten Ketapang [8].

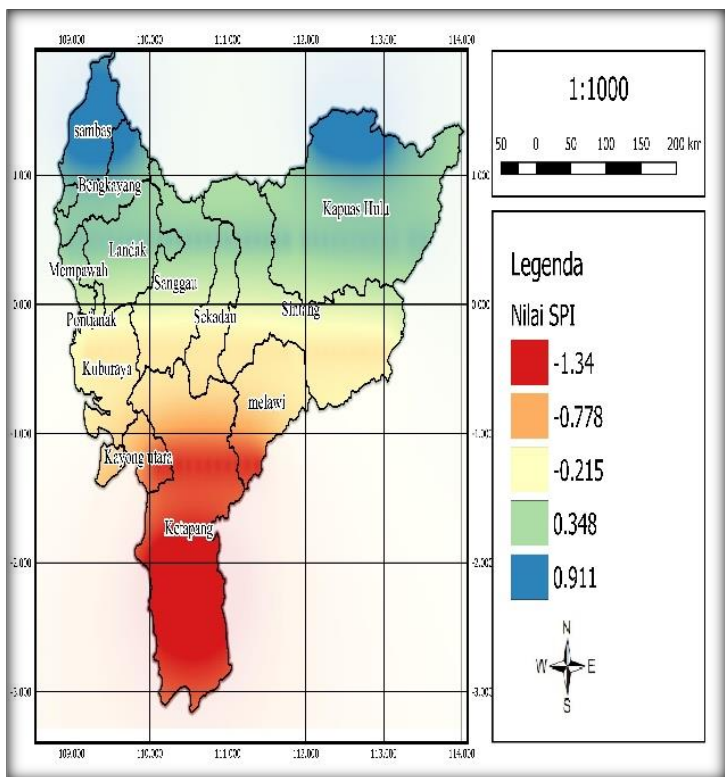

Gambar 3. Sebaran Kekeringan Tahun 2015

\subsection{Pola Distribusi Kekeringan Tahun 2016}

Pada Gambar 4 untuk tahun 2016 nilai SPI terkecil bernilai 0.45 dikategorikan normal dengan curah hujan sebesar $6892 \mathrm{~mm}$ yang terjadi di kabupaten Sambas, nilai indeks SPI tertinggi berada bernilai 3.21 dengan curah hujan sebesar 8469 yang dikategorikan sangat basah, terjadi di Kabupaten Melawi pada tahun 2016. Menurut Athoillah [8] terjadi fenomena La-Nina yang mengakibatkan curah hujan meningkat, pada fase La-Nina tersebut angin zonal yang berhembus dari utara-selatan membawa banyak uap air, hal inilah yang menyebabkan ada peningkatan curah hujan di Kabupaten Melawi sehingga pada tahun 2016 Kabupaten Melawi dikategorikan sangat basah. Selain fenomena El-Nino, faktor dominan yang mempengaruhi curah hujan di Kalimantan Barat adalah fenomena monsoon. Pada tahun 2016 monsoon yang terjadi adalah monsoon Asia, yang mengakibatkan terjadinya peningkatan curah hujan di Kalimantan Barat [7].

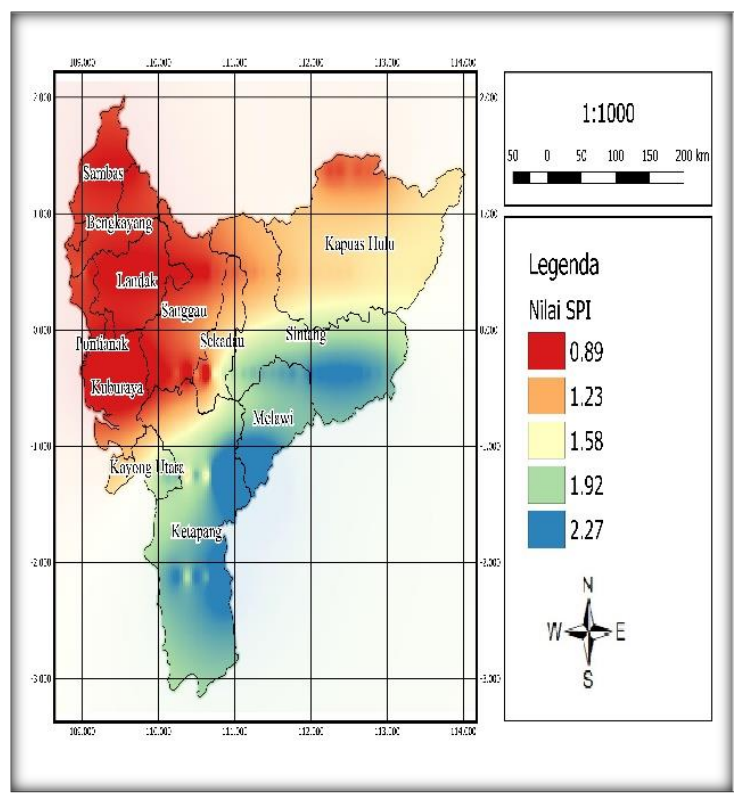

Gambar 4. Sebaran Kekeringan Tahun 2016

\section{Kesimpulan}

Dari pembahasan yang telah dipaparkan dapat disimpulkan bahwa, kekeringan yang terjadi pada tahun 2014 di Provinsi Kalimantan Barat telah diindikasikan dengan nilai indeks SPI sebesar -1.49 dengan curah hujan sebesar $3552 \mathrm{~mm}$, yang dikategorikan agak kering. Pada tahun 2015 kekeringan telah diindikasikan dengan nilai indeks SPI sebesar -1.306 dengan curah hujan sebesar $3862 \mathrm{~mm}$, yang dikategorikan agak kering. Pada tahun 2016 kekeringan telah diindikasikan dengan nilai indeks SPI sebesar 0.45 dengan curah hujan sebesar $6892 \mathrm{~mm}$, yang dikategorikan normal. Hasil analisi nilai indeks SPI dalam penelitian ini 
yang dihubungkan dengan penelitian sebelumnya telah menyimpulkan bahwa kekeringan yang terjadi ditahun 2014 dan 2015 disebabkan oleh fenomena iklim yaitu fenomena monsoon Australia dan El-Nino yang menyebabkan curah hujan berkurang dan pada tahun 2016 nilai indeks SPI meningkat disebabkan oleh fenomena monsoon Asia dan La-Nina yang mengakibatkan curah hujan meningkat.

\section{Daftar Pustaka}

[1] Wirjohamidjojo, S., 1988. Ragam Iklim di Bumi, s.l.: Buletin Met.

[2] Handoko, 1995. Klimatologi Dasar. Bogor: PT. Dunia Pustaka Jaya

[3] Wanisakdiyah, S., et al. 2017. Analisis Indeks Kekeringan Meteorologi Lahan Gambut di Pulau Tebing Tinggi Provinsi Riau Menggunakan Data Satelit Tropical Rainfall Measuring Mission (TRMM). JOM FTEKNIK. Volume IV.

[4] Afdeni, S,. et al. 2017. Analisis Indeks Kekeringan Meteorologi Lahan Gambut di Pulau Bengkalis. JOM FTEKNIK. Volume IV.

[5] McKee, T. D. N. \&. K. J., 1993. The relationship of drought frequency and duration to time scales. In: Proceedings of the Eight Conference on Applied Climatology, Anaheim, Clifornia, 17-22 January 1993. Boston: American Meteorological Society,179-184.

[6] Yuggtomo, M.E., dkk., 2014. Pengaruh Fenomena El-Nino dan Dipole Mode Terhadap Curah Hujan di Kabupaten Ketapang. Positron, volume IV.

[7] Visa, J., et al., 2010. Perilaku Curah Hujan di Kalimantan Barat (Pontianak, Ketapang, Putussibau, Sitang, Sambas). Prossiding Seminar Nasional Sains Atmosfer. Bandung.

[8] Athoillah, I., dkk., 2017. Analisis Spasial ElNino Kuat tahun 2015 dan La-Nina Lemah Tahun 2016 (Pengaruhnya Terhadap kelembapan, Angin dan Curah Hujan di Indonesia). Juenal Sains dan Teknologi Modifikasi Cuaca, Volume XVIII. 